\title{
Factors influencing maternal mortality among rural communities in southwestern Nigeria
}

\author{
This article was published in the following Dove Press journal: \\ International Journal of Women's Health \\ 10 April 2017 \\ Number of times this article has been viewed
}

\section{Dominic Ezinwa Azuh' \\ Akunna Ebere Azuh ${ }^{2}$ \\ Emeka Joshua Iweala ${ }^{3}$ \\ Davies Adeloye' \\ Moses Akanbi' \\ Raphael C Mordi ${ }^{4}$}

'Department of Demography and Social Statistics, ${ }^{2}$ Department of Estate Management, ${ }^{3}$ Biochemistry and Molecular Biology Unit, Department of Biological Sciences, ${ }^{4}$ Department of Chemistry, Covenant University, Ota, Ogun State, Nigeria
Correspondence: Dominic Ezinwa Azuh Department of Demography and Social Statistics, Covenant University, PMB 1023, Ota, Ogun State, Nigeria Tel +234805644 I06I

Email dominic.azuh@covenantuniversity. edu.ng
Background: Maternal mortality and morbidity reflect the status of population health and quality of life across nations. Poor understanding of the interplay of many antecedent factors, including sociocultural, economic and logistic factors, combined with an overwhelming poor health services delivery, is a basic challenge in several countries, particularly in rural settings where functional health care services are relatively scarce. There are still uncertainties as to the extent of this burden, owing to current challenges with information and data collation. This study aimed at identifying nonmedical factors associated with maternal mortality in rural and semiurban communities of southwestern Nigeria.

Methodology: The study was carried out in Ado-Odo/Ota Local Government Area of Ogun State. A multistage sampling technique and an informant survey approach were used in the study. A total sample of 360 eligible respondents were selected randomly from 11 out of 16 political wards in the study area and interviewed through the administration of questionnaires. The data were processed using descriptive statistics and regression analyses.

Results: Place of consultation ( $P=0.000)$, who pays the treatment costs $(P=0.000)$, awareness of pregnancy complications $(P=0.002)$ and knowledge of the place of antenatal care treatment $(P=0.000)$ significantly influenced maternal mortality (proxy by place of delivery of last birth). The $F$-statistic (15.100) confirmed the hypothesis that nonmedical factors influence maternal mortality. The correlation of predictor variables was significant at both the 0.01 level and the 0.05 level (2-tailed).

Conclusion: Our findings suggest that in a rural community setting with a depleted health care system, health education tailored toward community culture, subsidized maternal health care services by the government and operators of private clinics, as well as empowering and improving the status of women may reduce maternal mortality and prompt better utilization and survival chances of women in the study area as well as in all of Nigeria.

Keywords: maternal mortality, health care, nonmedical factors, informant approach, community

\section{Introduction}

Maternal mortality, which is widely accepted as a key indicator of population health and of socioeconomic development, ${ }^{1}$ is high in many African communities. Africa, particularly sub-Saharan Africa (SSA), has made insignificant progress toward reducing maternal mortality rate in the continent where almost half of the maternal deaths still occur. According to Babalola and Fatusi, ${ }^{2}$ Africa has the highest burden of maternal mortality in the world and SSA is largely responsible for the dismal maternal death figure for the region, contributing $\sim 66 \%$ of the maternal deaths for the region. ${ }^{3}$ Despite the progress made toward reduction in maternal mortality since the late 1980s, such as the International Safe Motherhood Initiative (SMI) in 1987, ${ }^{4}$ International Conference 
on Population and Development (ICPD) in $1994,{ }^{5}$ Fourth World Conference on Women, Beijing 1995, ${ }^{6}$ United Nations Millennium Development Goals (MDGs) 20007 and Sustainable Development Goals (SDGs) $2015,{ }^{8}$ in addition to other country-specific programs, many women and babies still die during pregnancy and childbirth in developing countries, including Nigeria.

The worrisome aspect of this situation is that in SSA, there has been no discernible or perceptible change over the past 2 or more decades. ${ }^{9}$ Akokuwebe and Okafor ${ }^{10}$ concluded that for real sustainable transformation of Nigeria, maternal health should be accorded priority through reducing the maternal mortality rate by the government and other stakeholders. The overwhelming majority of maternal deaths each year occur in developing countries in stark contrast to the situation in developed regions. According to the World Health Organization, ${ }^{3}$ developing regions accounted for $\sim 99 \%(302,000)$ of the global maternal deaths in 2015 , with SSA alone accounting for roughly $66 \%(201,000)$, followed by Southern Asia $(66,000)$. The problem of maternal mortality may be due to the interplay of many antecedent factors that could be sociocultural, economic or related to health care services and logistics. As observed by some authors, ${ }^{11,12}$ sociocultural factors and economic barriers may limit women's health seeking behavior, making pregnancy and childbirth precarious. Poor or broken down health systems hinder the progress of maternal mortality reduction and lead to high maternal deaths among mothers due to complications of pregnancy and childbirth. ${ }^{13,14}$ There is no single intervention measure that will considerably decrease maternal mortality, which indicates the need to examine factors other than medical causes, which are least studied, in order to understand comprehensively the factors affecting maternal health and mortality. Shah and Say ${ }^{9}$ noted that the trend in developing countries is much worse now than when the SMI was launched in Kenya in 1987. The increasing burden of poor institutional health care services delivery presents mothers with multiple challenges during pregnancy and delivery, leading to high maternal mortality in developing countries. Maternal mortality statistics remain very high in Nigeria; in fact, it is one of the highest in the world after India. ${ }^{15-17}$ Nigeria needs immediate intervention to reduce her unacceptably high levels of maternal deaths. The situation is even grave in rural areas in Nigeria where the health care system is poor and overstretched, in addition to the poverty level being high. According to the Nigeria Demographic and Health Survey (NDHS), 63\% of deliveries occur at home and only a small proportion (38\%) of women in Nigeria is attended to at delivery by a skilled attendant. ${ }^{18}$ The health of mothers is very crucial because it has a bearing on the health of every member of the household, particularly that of children and aged persons. Undoubtedly, regional variation in factors affecting the utilization of maternal health services across the 6 geopolitical zones of Nigeria has been observed; ${ }^{19,20}$ the situation perhaps may be worse in rural and semiurban areas where there is a low proportion of functional primary health care facilities and patronage.

Several studies have documented the scarcity of reliable and accurate data on maternal mortality, ${ }^{16,17}$ particularly in developing countries, where the maternal mortality is high. According to Ujah et al, ${ }^{21}$ knowledge of maternal mortality has been mainly derived from data provided by urban hospitals. Statistics on nonmedical factors, such as information on social, economic, cultural and behavioral factors, contributing to maternal mortality are rarely available, especially at the community level. One important fact is that the dynamics of maternal health and mortality are yet to be fully comprehended in Nigeria. Understanding the real situation of a mother's disease condition and death is vital in dealing with the challenge of uncompromising high maternal mortality rates in Nigeria. Although community-based studies are few in Nigeria, ${ }^{17}$ most of the available studies provide mainly fragmentary hospital-based information, which is not representative in nature, as the majority of deliveries are conducted at home by traditional birth attendants (TBAs) or relatives as indicated earlier. Hence, an innovative community-based approach to unearth the nonmedical factors influencing deaths and morbidity among mothers in communities in Ado-Odo/Ota Local Government Area (LGA) in Ogun State, Nigeria, becomes imperative.

The main objective of this study was to determine the nonmedical factors that influence maternal mortality in the study area and to identify the nonmedical determinants that will provide baseline data for future investigation into maternal mortality and its contributing factors in the region. It will also aid in adopting interventions on maternal health services and policies for improving the management and reduction of maternal mortality in Ado-Odo/Ota LGA and, by extension, the entire country.

\section{Methodology}

This study engaged a multistage design and an informantbased survey because of its sensitive nature. Ado-Odo/Ota LGA was selected purposively out of 20 LGAs in Ogun State, Nigeria. In the second stage, all the political wards were listed, and 11 were randomly selected out of 16 wards. 
Interviews were conducted in these 11 randomly selected wards; identified households in these wards were visited to collect information from eligible respondents for the quantitative study. Eligible respondents consisted of husbands whose wives had died during pregnancy, in the course of delivery or 42 days thereafter in the 3 years preceding the survey. The study used a structured questionnaire designed to elicit the required information from eligible respondents that met the above criteria. Informants were employed to aid in locating respondents through the assistance of health workers in hospital/primary health centers and TBAs' facilities. Where the husband was not available, a close sister or head of household who was fully aware of the case was approached for eliciting information on maternal death and issues related to it as contained in the research instrument. The sample size was 360 eligible respondents. The data collection instrument was pretested for reliability and validity, and necessary modifications and revisions were carried out to perfect its reliability. Interrater reliability was used, and ratings from 2 independent raters were correlated; the index yielded $r=0.64$, whereas the Cronbach's alpha index yielded a value of 0.68 . The construct validity of the instrument was guaranteed by a demographer and health care personnel. The data were analyzed with the aid of IBM SPSS Statistics 19 (IBM Corporation, Armonk, NY, USA).

In addition, for qualitative data collection, focus group discussions (FGDs) were conducted among stakeholders The FGD participants (FGDPs) were drawn from 4 groups, namely, 1) TBAs and faith-based birth attendants (FBBAs), 2) community health workers (CHWs) comprising nurses and midwives, 3) pregnant women attending the antenatal care (ANC) clinic and 4) community development associations (CDAs). These stakeholders were considered to be associated with pregnancy (pre- and postpregnancy issues) and child delivery in the study area. The essence was to harvest the experiences of the participants on maternal mortality and morbidity in the study location. Twelve persons constituted the group and the meeting lasted for 55 minutes. Common discussion guidelines that were designed to gather information on the factors influencing maternal mortality based on maternal health care practices and problems, decision on choice of place of institutional delivery, payment of treatment costs, awareness of pregnancy complications and knowledge of place of ANC treatment were engaged in the exercise, and all the rules of FGDs were followed. The discussions were led by a good moderator who had some experience in the conduct of FGDs. A notetaker and a video recording device were used to capture all information, and the moderator followed a discussion guide. Taped recordings during FGDs were transcribed and compared with the notes taken for completeness. Transcripts were coded according to participants' responses to each question, and the most salient themes emerged across the set of discussions. The data in local language were translated by a skilled translator into English language and analyzed using content analysis.

This study did not require ethics committee approval. However, informed consent was obtained from all respondents before the interview. Respondents were informed of the purpose of the study, assured of confidentiality of information supplied. In addition, a request was made not to answer any question they were not willing to and could stop the interview at will.

\section{Results \\ Sociodemographic characteristics of respondents (husbands) and deceased spouses}

The age at first marriage of respondents was highest between ages 25 and 44 years with a proportion of $64.2 \%$ (Table 1). The occupational status of the husbands interviewed ranged from unskilled labor (15\%), skilled artisans (32.2\%), traders $(23.3 \%)$ and farmers $(11.4 \%)$ to civil servants $(10.6 \%)$. Overall, $89.4 \%$ belonged to the working class, while only $7.5 \%$ were not working as at the time of the survey. The highest level of education attained by the majority of the respondents interviewed was primary education (49.7\%), followed by secondary education $(29.2 \%)$. However, respondents with no school and with postsecondary education accounted for $16.1 \%$ and $5 \%$, respectively.

Incidentally, the age at first marriage of deceased spouses was highest between ages 15 and 29 years with the same proportion of $64.2 \%$. Regarding the occupational status of the deceased spouse, those working comprised the highest proportion $(74.5 \%)$, followed by full-time housewives (25.5\%). When reference was made to the education of their deceased spouses, a similar scenario was observed: $50 \%$ of them had had only primary education, followed by those who attained secondary school (27.5\%) and those who never went to school (18.9\%). Nevertheless, those who attained postsecondary education were the least (3.6\%).

Respondents who had health facilities close to their homes $(<2-3 \mathrm{~km})$ accounted for the least $(10.3 \%)$, those who had the health facility at a distance of $4-5 \mathrm{~km}$ accounted for $14.5 \%$ and about three-fourths $(75.2 \%)$ of the respondents had to travel $6 \mathrm{~km}$ and beyond to access 
Table I Sociodemographic characteristics of respondents and deceased spouses

\begin{tabular}{|c|c|c|c|c|c|}
\hline \multicolumn{3}{|l|}{ Respondent } & \multicolumn{3}{|l|}{ Deceased spouse } \\
\hline & Number & Percentage & & Number & Percentage \\
\hline \multicolumn{3}{|c|}{ Age at first marriage, years } & \multicolumn{3}{|c|}{ Age at first marriage of deceased, years } \\
\hline $15-24$ & 21 & 5.8 & $15-19$ & 95 & 26.4 \\
\hline $25-34$ & 120 & 33.4 & $20-29$ & 136 & 37.8 \\
\hline $35-44$ & 111 & 30.8 & $30-39$ & 83 & 23.0 \\
\hline $45-54$ & 63 & 17.5 & $\geq 40$ & 46 & 12.8 \\
\hline$\geq 55$ & 45 & 12.5 & & & \\
\hline \multicolumn{3}{|l|}{ Occupational status } & \multicolumn{3}{|c|}{ Deceased's occupation } \\
\hline Civil service & 38 & 10.6 & Full-time housewife & 92 & 25.6 \\
\hline Labor/unskilled & 54 & 15.0 & Laborer/unskilled & 52 & 14.4 \\
\hline Skilled artisan & 116 & 32.2 & Artisan & 47 & 13.0 \\
\hline Trading & 84 & 23.3 & Trading & 91 & 25.3 \\
\hline Peasant farming & 41 & $1 \mathrm{I} .4$ & Peasant farming & 78 & 21.7 \\
\hline Unemployed & 27 & 7.5 & & & \\
\hline \multicolumn{3}{|c|}{ Educational attainment } & \multicolumn{3}{|c|}{ Deceased's educational attainment } \\
\hline No schooling & 58 & 16.1 & No schooling & 68 & 18.9 \\
\hline Up to primary level & 179 & 49.7 & Up to primary level & 180 & 50.0 \\
\hline Up to secondary level & 103 & 29.2 & Up to secondary level & 99 & 27.5 \\
\hline Postsecondary level & 18 & 5 & Postsecondary level & 13 & 3.6 \\
\hline \multicolumn{6}{|c|}{ Distance to health facility } \\
\hline$<2 \mathrm{~km}$ & 9 & 2.5 & & & \\
\hline $2-3 \mathrm{~km}$ & 28 & 7.8 & & & \\
\hline $4-5 \mathrm{~km}$ & 52 & 14.5 & & & \\
\hline$\geq 6 \mathrm{~km}$ & 271 & 75.2 & & & \\
\hline \multicolumn{6}{|c|}{ Social class of respondent } \\
\hline Upper class & 2 & 0.6 & & & \\
\hline Middle class & 118 & 32.8 & & & \\
\hline Lower class & 240 & 66.6 & & & \\
\hline
\end{tabular}

Note: $\mathrm{N}=360$.

health care services. On examination of the social class of the respondents, it was observed that respondents in the study area belonged to the poor social class, as majority of them belonged to the low class category (66.6\%), followed by a reasonable proportion in the middle class category $(32.8 \%)$ and negligible proportion in the upper class $(0.6 \%)$ cadre.

\section{Factors influencing maternal morbidity and mortality}

An overwhelming proportion (80.3\%) agreed that malaria and fever were the most common ailments in the study locations (Table 2). The remaining proportion was accounted for by typhoid (13.9\%), headache (1.9\%), cold/cough (3.3\%), diarrhea $(0.3 \%)$ and diabetes $(0.3 \%)$. In the study area, $49.7 \%$ of the respondents stated that it was the husband's responsibility to pay for the treatment costs. This was followed by relatives $(25 \%)$, others $(11.7 \%)$, both respondent and spouse (8.9\%) and finally spouse (wife) (4.7\%). Places of consultation visited by the respondents showed that slightly more than half of them approached medical personnel (51.4\%), and nonmodern consultation accounted for $48.6 \%$. The noninstitutional consulting homes included homes of traditional healers ( $12.2 \%$ ), pastors (2.8\%), family members $(5.8 \%)$ and self $(27.8 \%)$. An overwhelming proportion of the respondents $(90.8 \%$ ) admitted knowledge of place of ANC treatment. The assistance during pregnancy and childbirth is also encouraging as $71.9 \%$ of respondents acknowledged the services of medical personnel at delivery as against $28.1 \%$ who still availed themselves of the services of nonmedical personnel during delivery. The study revealed that $36.4 \%$ of the husbands preferred $1-4$ children as ideal and $52.2 \%$ preferred $\geq 5$ children. While a preponderance of the respondents' wives had institutional delivery (71.7\%), most of these deliveries were concentrated in the private hospitals/clinics (42.2\%). Only $29.5 \%$ of the respondents' wives attended government health centers during delivery. However, a worrisome number $(28.3 \%$ ) had noninstitutional delivery. Awareness of pregnancy complications among the respondents was substantial (49.4\%). However, just more than half the respondents $(50.6 \%)$ had no awareness of pregnancy complications.

The multivariate analysis results further buttress these findings from the study (Table 3 ). The results showed that 
Table 2 Factors influencing maternal morbidity and mortality

\begin{tabular}{|c|c|c|c|c|c|}
\hline Variable & Number & Percentage & Variable & Number & Percentage \\
\hline Common ailment & & & \multicolumn{3}{|c|}{ Who pays the treatment cost } \\
\hline Malaria/fever & 289 & 80.3 & Husband & 179 & 49.7 \\
\hline Cold/cough & 12 & 3.3 & Spouse & 17 & 4.7 \\
\hline Headache & 7 & 1.9 & Both & 32 & 8.9 \\
\hline Diabetes & I & 0.3 & Relatives & 90 & 25.0 \\
\hline Diarrhea & 1 & 0.3 & Others (friends) & 42 & 11.7 \\
\hline Typhoid & 50 & 13.9 & \multicolumn{3}{|c|}{ Knowledge of place of ANC treatment } \\
\hline Place of consultation & & & Yes & 327 & 90.8 \\
\hline Medical personnel & 185 & 51.4 & No & 33 & 9.2 \\
\hline Traditional healer & 44 & 12.2 & \multicolumn{3}{|c|}{ Provider of ANC assistance } \\
\hline Pastor & 10 & 2.8 & Medical personnel & 259 & 71.9 \\
\hline Family member & 21 & 5.8 & Nonmedical personnel & 101 & 28.1 \\
\hline Self & 100 & 27.8 & \multicolumn{3}{|l|}{ Cost of ANC services } \\
\hline Family size & & & Not expensive & 75 & 20.8 \\
\hline I-2 children & 30 & 8.3 & Expensive & 285 & 79.2 \\
\hline 3-4 children & 101 & 28.1 & \multicolumn{3}{|c|}{ Awareness of pregnancy complications } \\
\hline 5-6 children & 113 & 31.4 & Yes & 178 & 49.4 \\
\hline$\geq 7$ children & 75 & 20.8 & No & 182 & 50.6 \\
\hline No response & 41 & 11.4 & & & \\
\hline \multicolumn{6}{|l|}{ Place of last delivery } \\
\hline Institutional (government) & 106 & 29.5 & & & \\
\hline Institutional (private clinic) & 152 & 42.2 & & & \\
\hline Noninstitutional & 102 & 28.3 & & & \\
\hline
\end{tabular}

Abbreviation: ANC, antenatal care.

place of consultation $(P=0.000)$, who pays the treatment costs ( $P=0.000)$, awareness of pregnancy complications $(P=0.002)$ and knowledge of place of ANC treatment $(P=0.000)$ are significant to the outcome of the place of delivery, which is a proxy for maternal mortality. From the analysis of variance (ANOVA), there was also a significant relationship between these variables and the dependent variable, the place of delivery of last birth. The $F$-statistic (15.100) confirmed the hypothesis that nonmedical factors were significantly related to maternal mortality among the women in the study area. The correlation of predictor variables (Table 4 ) was significant at the 0.01 level and at the 0.05 level (2-tailed).

\section{Findings from the qualitative study}

The report from the qualitative study showed the factors influencing maternal mortality as reflected by awareness of pregnancy complications, knowledge of place of ANC treatment, who pays the treatment costs and place of delivery practices among others. The FGDPs were drawn from 4 groups, namely 1) TBAs and FBBAs, 2) CHWs comprising nurses and midwives, 3) pregnant women attending the ANC clinic and 4) CDAs. The CDA creates awareness on health and environmental sanitation issues. It is an advocacy association that popularizes health programs among communities in the study area. All these categories were considered to be associated

Table 3 ANOVA showing the relationship of predictors and place of delivery of last birth (maternal mortality)

\begin{tabular}{|c|c|c|c|c|c|}
\hline Model & Sum of squares & $d f$ & Mean square & $\boldsymbol{F}$ & Sig \\
\hline Regression & 86.197 & 4 & 21.549 & 15.100 & 0.000 \\
\hline Residual & 430.988 & 302 & 1.427 & - & - \\
\hline Total & 517.186 & 306 & & & \\
\hline \multirow[t]{2}{*}{ Variables } & \multicolumn{2}{|c|}{ Unstandardized coefficients } & Standardized coefficients & $t$ & Sig \\
\hline & B & Std error & Beta & & \\
\hline (Constant) & 4.047 & 0.475 & - & 8.526 & 0.000 \\
\hline Place of consultation & 0.188 & 0.033 & 0.305 & 5.767 & 0.000 \\
\hline Who pays the treatment costs & -0.010 & 0.003 & -0.206 & -3.876 & 0.000 \\
\hline Awareness of pregnancy complications & 0.405 & 0.138 & 0.156 & 2.926 & 0.004 \\
\hline Knowledge of place of ANC treatment & -1.314 & 0.405 & $-0.17 \mid$ & -3.243 & 0.001 \\
\hline
\end{tabular}

Abbreviations: ANC, antenatal care; ANOVA, analysis of variance; Sig, significance; Std, standard. 
Table 4 Correlations of predictor variables

\begin{tabular}{|c|c|c|c|c|}
\hline Variables & $\begin{array}{l}\text { Who pays the } \\
\text { treatment costs }\end{array}$ & $\begin{array}{l}\text { Place of } \\
\text { consultation }\end{array}$ & $\begin{array}{l}\text { Awareness of pregnancy } \\
\text { complications }\end{array}$ & $\begin{array}{l}\text { Knowledge of place } \\
\text { of ANC treatment }\end{array}$ \\
\hline \multicolumn{5}{|c|}{ Who pays the treatment costs } \\
\hline Pearson's correlation & I & -0.013 & $0.157^{* *}$ & -0.049 \\
\hline Sig (2-tailed) & - & 0.803 & 0.003 & 0.367 \\
\hline $\mathrm{N}$ & 360 & 360 & 360 & 336 \\
\hline \multicolumn{5}{|l|}{ Place of consultation } \\
\hline Pearson's correlation & -0.013 & 1 & $-0.111 *$ & 0.027 \\
\hline Sig (2-tailed) & 0.803 & & 0.035 & 0.626 \\
\hline$N$ & 360 & 360 & 360 & 336 \\
\hline \multicolumn{5}{|c|}{ Awareness of pregnancy complications } \\
\hline Pearson's correlation & $0.157 * *$ & $-0.111 *$ & I & 0.027 \\
\hline Sig (2-tailed) & 0.003 & 0.035 & & 0.617 \\
\hline$N$ & 360 & 360 & 360 & 336 \\
\hline \multicolumn{5}{|c|}{ Knowledge of place of ANC treatment } \\
\hline Pearson's correlation & -0.049 & 0.027 & 0.027 & 1 \\
\hline Sig (2-tailed) & 0.367 & 0.626 & 0.617 & - \\
\hline$N$ & 336 & 336 & 336 & 336 \\
\hline
\end{tabular}

Notes: *Correlation is significant at the 0.05 level (2-tailed). ${ }^{* *}$ Correlation is significant at the 0.01 level (2-tailed).

Abbreviations: ANC, antenatal care; Sig, significance.

with pregnancy (pre- and postpregnancy issues) and child delivery. Below are some excerpts from the FGDs.

\section{Pregnancy complications}

Certainly, the majority of participants (50.6\%) had no knowledge of pregnancy complications; almost half (49.4\%) of them, however, had awareness regarding the same (Table 2). The evolved theme was as follows: higher knowledge of pregnancy complications reduced pregnancy complications and enhanced the use of institutional delivery. FGDs also supported this claim, though not all concurred.

The problems of pregnancy are plenty. The problem of hypertension and malaria that make me lost 2 pregnancies. Sometimes pregnant woman get stress, high blood pressure, baby in the stomach, bleeding, restlessness, lost of pregnancy, swelling for face and legs, and lack of blood are common problems of pregnancy. When I get pregnant I have miscarriage because of stress and lack of using the drugs given to me in the clinic. Some people when they are pregnant will start vomiting and will be advised not to have sexual intercourse until about 4 or 5 months to avoid losing the baby. [sic] [FGDP, 37 year old from Ota]

Another participant revealed:

I don't know whether pregnancy complication exist in this area but know that not all women that get pregnant survive the journey. [sic] [FGDP, 35 year old from Ota]

Another participant, corroborating, said that
Pregnancy complications in this area are common and hypertension and bleeding and baby outside womb sometime prolonged labor occurs. In some cases they leads to death, and TBA provider won't do anything. [sic] [FGDP, 36 year old from Ota]

\section{Knowledge of place of ANC treatment}

The knowledge of place of ANC treatment is interesting as an overwhelming proportion of the respondents admitted knowledge of it $(90.8 \%)$, but a small proportion posited that they were unaware (Table 2). However, most of them visited the ANC treatment place to get a card in case of emergency and not because they use the facility. Perhaps this might be the reason why noninstitutional delivery and providers exist, as seen in Table 2.

We know about health clinic for ANC treatment. We go there sometimes to book and get card because nurse will demand your card for emergency. If you don't come with card the nurses will talk rudely to you and you cannot see the doctor. [sic] [FGDP, 30 year old from Ota]

\section{Place of delivery, payment of treatment cost and why pregnant women patronize noninstitutional delivery}

The majority of the respondents preferred institutional delivery (71.7\%) and ANC providers (71.9\%) (Table 2). Nevertheless, a substantial number of participants indicated that they preferred noninstitutional delivery. Assistance 
by nonmedical providers leads to low quality of services, which could have resulted in pregnancy complications and maternal deaths among the deceased wives of respondents in the study area. Several reasons, such as cost, quality of service, satisfaction, as well as proximity and transportation issues, were given for the use of nonmedical facilities. FGDPs mentioned husbands and relatives, and sometimes friends, as sources of their money. The theme derived is that the chance of maternal mortality is higher among nonusers of institutional facilities due to poor knowledge of pregnancy complications, among others.

Our health center is far and no transport. We like local delivery because they treat us fine and when pregnancy come we walk to Baba doctor's place (TBA's home) No body walk to clinic when delivery come. [sic] [FGDP, 33 year old from Ota]

Another participant was quick to add:

Baba doctor give big medicine and collects money small by small. His home is close by walk and often he comes to conduct delivery in our houses. [sic] [FGDP, 39 year old from Ota]

\section{A CDA participant revealed that}

Noninstitutional deaths are not uncommon in this community due to complications of pregnancy and delivery. My friend's wife died when giving birth because bleeding was high and blood was not available. [sic] [FGDP, 38 year old from Ota]

The hospital people will ask us pay big money and we will ask our husbands because they provide money us and women don't have money. Sometimes our relatives and friends give us money for clinic. If we do not get the money from our husbands we don't go to hospital because they will send us back and not treat us even in serious condition. [sic] [FGDP, 35 year old from Ota]

Another participant revealed that

even when formal health fees are low, other informal costs such as buying complete delivery items, drugs and food pose barriers to the utilization of available health services. [sic] [FGDP, 41 year old from Ota]

Corroborating this claim, a nursing sister from one of the health facilities observed that

Some of the women who delivered in noninstitutional homes cannot afford the minimum charges of government health centers but the risk of complications and maternal deaths may be very high for those attending noninstitutional homes. [sic] [FGDP, 40 year old from Ota]

\section{Discussion}

Marriage exposes a woman to the risk of pregnancy, and early marriage puts a woman into longer exposure to pregnancy and child delivery complications. ${ }^{18}$ The age at first marriage of respondents was highest between ages 25 and 44 years with a proportion of $64.2 \%$ (Table 1). Incidentally, the age at first marriage of deceased spouses was highest between ages 15 and 29 years with the same proportion of $64.2 \%$. This means that the age at first marriage of deceased spouses was relatively low compared to that of their husbands. The low age at first marriage has also been noted in earlier studies. ${ }^{22-26}$

Comparatively, education and occupation, though low, showed that respondents were better off than their deceased spouses, a strong indication of the low status of women in the study area. The poor socioeconomic class of the respondents also buttressed the poor social class of respondents (66.6\%). The association of maternal education with empowerment and knowledge of safe motherhood practices, leading to reduction in maternal mortality, has been observed by other scholars. ${ }^{27,28}$ The social status of respondents in the study population needs urgent attention as this might adversely affect access to health care services, leading to high maternal morbidity and mortality. The study revealed that distance to the health facility was also a major retarding factor in accessing health care services among the wards in the study area, ${ }^{13,29-31}$ and the situation is disturbing as an overwhelming proportion $(75.2 \%)$ of respondents indicated that they had to travel $\geq 6 \mathrm{~km}$ and to access health care services. A pregnant woman would prefer to visit the next-door TBA rather than walk for kilometers to the health center where she had no confidence in the service, ${ }^{31}$ as equally revealed during the FGDs. Similar observations were reported by other researchers previously. ${ }^{30,32}$

Factors influencing maternal morbidity and mortality (Table 2) revealed interesting findings. An overwhelming majority $(80.3 \%)$ agreed that malaria and fever were the most common ailments in the study locations. Payment of hospital bills was exclusively within the domain of the respondents (husbands). Culturally, in a patriarchal society such as Nigeria, male dominance and women subjugation are normal ways of life. In the study area, $49.7 \%$ of the respondents stated that it was their responsibility to pay for the treatment costs. This is also a restraining force to accessing health care facilities by pregnant women as it increases the dependency syndrome of wives. This relates to the statement 
from FGDPs that if their husbands did not give them money for the clinic, they would not avail the services of the ANC center, the consequence of which is grave. The payment of cost of ANC services has great bearing on utilizing the health facility. Cost may reduce women's use of maternal health services and refrain them from having hospital-based deliveries or seeking care even when complications arise. ${ }^{31}$ Information gathered through FGDs revealed that even when formal fees are low, other informal costs such as buying complete delivery items, drugs, food, and so on pose barriers to the utilization of available health services. This calls for government subsidizing the health care cost and bringing health facility closer to the masses.

Places of consultation chosen by the respondents showed that slightly more than half of them used medical personnel (51.4\%), and nonmodern consultation, including self, accounted for $48.6 \%$. The noninstitutional consulting homes included homes of traditional healers, pastors and relatives, which attracted a reasonable proportion $(20.8 \%)$. It is noteworthy that $27.8 \%$ of the respondents diagnosed their illness by themselves without recourse to institutional consultation. This is worrisome, particularly when we consider the dangerous consequences of such practice in Nigeria. The awareness regarding place of ANC treatment is fascinating and encouraging as an overwhelming proportion of the respondents (90.8\%) admitted knowledge of place of ANC treatment. This level of knowledge should be made to translate into practice the terms of reducing pregnancy complications and home delivery in the study area. The assistance during pregnancy and childbirth is also encouraging as $71.9 \%$ of respondents acknowledged the services of medical personnel at delivery, as against $28.1 \%$ who still availed themselves of the services of nonmedical personnel during delivery. Undoubtedly, this proportion of mothers patronizing home delivery services is high, just as for the whole of Nigeria, ${ }^{18}$ considering the low quality of services rendered by these categories of health providers in a country beset with dismal health services, ${ }^{31}$ which could have resulted in pregnancy complications and maternal deaths among the deceased wives of respondents in the study area.

The study revealed that $36.4 \%$ of the husbands preferred $1-4$ children as ideal and $52.2 \%$ preferred $\geq 5$ children. The perception showed an inclination toward multiple pregnancies among the respondents. This high preference for higher family size exposed women to higher risk of maternal deaths and apparently portrays the low status of women. This is in line with the observation on the prevailing situation in SSA nations. ${ }^{3}$ Despite high institutional delivery $(71.7 \%)$ among respondents' wives, both at government and private hospitals, the study revealed that a reasonable proportion of wives still patronized noninstitutional deliveries as in the case of the larger society, ${ }^{18}$ due to several factors ranging from difficulty in payment of hospital bills, distance to the health facility and unfriendly attitude of health care workers to poor quality of services, among others. These findings from both quantitative and qualitative dimensions corroborate the results of other previous studies within and outside Nigeria. ${ }^{2,33-36}$ Hence, considering the findings herein and the level of poverty in Nigeria, the government should subsidize rural health care services and establish midway service delivery points (MSDPs) to reduce the problem of distance and further bring Grass Roots Health Care services closer to the rural population. The study revealed some basic awareness of pregnancy complications among respondents (49.4\%), as well as during FGDs; slightly more than half of the respondents $(50.6 \%)$ had no awareness of pregnancy complications. This situation might lead to serious issues during pregnancy and calls for health education in order to reduce the hazards that accompany ignorance of pregnancy complications.

The findings from the multivariate analysis survey also revealed that place of consultation $(P=0.000)$, who pays the treatment costs $(P=0.000)$, awareness of pregnancy complications $(P=0.002)$ and knowledge of place of ANC treatment $(P=0.000)$ are significant to the place of delivery, which is a proxy to maternal mortality. The place of consultation reflects the tendency to use the place for delivery, thereby influencing the provision of assistance during pregnancy and after childbirth. It is therefore important to ensure institutional consulting among women during pregnancy. The absence of these maternal ingredients was tantamount to poor survival chances among pregnant women in the study community. In addition, modern health care services cost money, and the lower social status of the household as well as that of women discourage the wife from seeking modern medical services. Results of the ANOVA showed that there is also a significant relationship between these variables and the dependent variable, the place of delivery of last birth. The $F$-statistics (15.100) confirmed the hypothesis that nonmedical factors were significantly related to maternal mortality among the women in the study area. The correlation of predictor variables (Table 4) was significant at the 0.01 level and at the 0.05 level (2-tailed).

\section{Conclusion}

Maternal mortality in Nigeria continues to be a serious public health problem and contributes to the low life expectancy 
among women in Nigeria. This study has identified several factors that have an important influence on maternal mortality in the study area. Among these are variables such as place of consultation/diagnosis, the person who pays the treatment costs, awareness of pregnancy complications and knowledge of the place of ANC treatment, among others. The FGD technique was beneficial and provided qualitative insight on factors influencing maternal mortality and prospects of pregnancy care intervention programs. Many women preferred noninstitutional delivery. Long distance was mentioned as one of the reasons for respondents' preference for home delivery or noninstitutional delivery, in addition to the cost of medical treatment, poor treatment at health care clinics and the harsh attitudes of health care providers.

The findings from this study may help government, civil society organizations/nongovernmental organizations and private organizations to design comprehensive interventions toward reducing the high maternal mortality in the study area and, by extension, the entire country. The government should subsidize health care services and establish MSDPs to reduce the problem of distance and further bring grass roots health care services closer to the rural population. Health education and mass enlightenment should be strengthened to create greater awareness on pregnancy complications and zero noninstitutional delivery tolerance. Empowering and improving the status of women may reduce maternal mortality, prompt better utilization and increase the survival chances of women in the study area. In addition, government should train TBAs to reduce their limitations and improve on their performance. The outcome of this study will be made known to the local government and equally disseminated to the communities in the study area.

\section{Acknowledgments}

The authors appreciate the editorial comments and suggestions of Prof C Awonuga from the Department Modern Languages, Covenant University. We also acknowledge members of the Covenant University editorial team for their assistance in improving the quality of this work.

\section{Author contributions}

DEA conceived the idea of the article. All the authors provided substantial contribution to the design, acquisition of data, analysis and interpretation and revision of drafts and gave their final approval for the final version of the manuscript.

\section{Disclosure}

The authors report no conflicts of interest in this work.

\section{References}

1. Envuladu EA, Agbo HA, Lassa S, Kigbu JH, Zoakah AI. Factors determining the choice of a place of delivery among pregnant women in Russia village of Jos North, Nigeria: achieving the MDGs 4 and 5. Int J Med Biomed Res. 2013;2(1):23-27.

2. Babalola S, Fatusi A. Determinants of use of maternal health services in Nigeria: looking beyond individual and household factors. $B M C$ Pregnancy Childbirth. 2009;9(43):1-13.

3. World Health Organization. Trends in Maternal Mortality: 1990 to 2015. Estimates Developed by WHO, UNICEF, UNFPA, World Bank and UN Population Division. Geneva: World Health Organization; 2015.

4. Starrs A. Preventing the Tragedy of Maternal Deaths: A Report on the International Safe Motherhood Conference Nairobi Kenya. World Bank Publications; 1987.

5. United Nations. Report of the International Conference on Population and Development, Cairo, 5-13 September 1994. New York: United Nations Publications; 1995. Available from: https://www.unfpa.org/ sites/default/files/event-pdf/icpd_eng_2.pdf.

6. United Nations. Report of the Fourth World Conference on Women Beijing, 4-15 September 1995. New York: UN; 1996. Available from: www.un.org/womenwatch/daw/beijing/pdf/Beijing\%20full $\% 20$ report\%20E.pdf.

7. United Nations. Millennium Summit (6-8 September 2000). United Nations HQ. New York: UN; 2000. Available from: http://www.un.org/ en/events/pastevents/millennium_summit.shtml.

8. United Nations. United Nations Sustainable Development Summit 2015, 25-27 September 2015, New York. Available from: https:// sustainabledevelopment.un.org/post2015/summit.

9. Shah IH, Say L. Maternal mortality and maternal care from 1990-2005: uneven but important gains. Maternal mortality and morbidity: is pregnancy getting safer for women? Reprod Health Matters. 2007;15(30): $17-27$.

10. Akokuwebe ME, Okafor EE. Maternal health and the implications for sustainable transformation in Nigeria. Res Humanit Soc Sci. 2015; $5(6): 1-13$

11. Olaku DA. High-Risk Pregnancies and Perceptions of Maternal Mortality among Women in Plateau State of Nigeria [MSc thesis]. Zaria Nigeria: Ahmadu Bello University; 2014.

12. Adeusi SO, Adekeye OA, Ebere LO. Predictors of maternal health as perceived by pregnant women in Eti-Osa, Lagos State. Nigeria J Educ Pract. 2014;5(18):125-131.

13. Federal Ministry of Health (FMOH). Integrated Maternal, Newborn and Child Health Strategy. Abuja: Federal Ministry of Health; 2007.

14. Nigeria Federal Ministry of Health (NFMOH). Technical Report on National Study on Essential Obstetric Care Facilities in Nigeria. Abuja, Nigeria: Federal Ministry of Health; 2003.

15. Federal Ministry of Health (FMOH). Road Map for Accelerating the Attainment of the MDGs Related to Maternal and Newborn Health in Nigeria. Abuja: FMOH; 2006.

16. World Health Organization. Trends in Maternal Mortality: 1990 to 2008. Estimates Developed by WHO, UNICEF, UNFPA and World Bank. Geneva: World Health Organization; 2010.

17. Adegoke AA, Campbell M, Ogundeji MO, Lawoyin TO, Thomson AM. Community study of maternal mortality in South West Nigeria: how applicable is the sisterhood method. Matern Child Health J. 2012; 17(2):319-329.

18. National Population Commission (NPC) [Nigeria] and ICF Macro. Nigeria Demographic and Health Survey 2013. Abuja: NPC and ICF Macro; 2014.

19. Adamu HS. Utilization of Maternal Health Care Services in Nigeria: An Analysis of Regional Differences in the Patterns and Determinants of Maternal Health Care Use [dissertation]. England: The University of Liverpool; 2011.

20. Chubike NE, Constance I. Demographic characteristics of women on the utilization of maternal health services at Abakaliki Urban. Int $J$ Nurs Midwifery. 2013;5(8):139-144. 
21. Ujah IAO, Aisien OA, Mutihir JT, Vanderagt DJ, Glew RH, Uguru VE. Factors contributing to maternal mortality in north-central: a seventeenyear review. Afr J Reprod Health. 2005;9(3):27-40.

22. Fagbamigbe AF, Idemudia ES. Barriers to antenatal care use in Nigeria: evidences from non-users and implications for maternal health programming. BMC Pregnancy Childbirth. 2015;15(95):2-10.

23. Raj A, Boehmer U. Girl child marriage and its association with national rates of HIV, maternal health, and infant mortality across 97 countries. Violence Against Women. 2013;19(4):536-551.

24. Patton GC, Coffey C, Sawyer SM, et al. Global patterns of mortality in young people: a systematic analysis of population health data. Lancet. 2009;374(9693):881-892.

25. Nour NM. Health consequences of child marriage in Africa: emerging infectious diseases. EID J. 2006;12(11):1644-1649.

26. United Nations Fund for Population Activities [webpage on the Internet]. State of World population; 2004. Available from: http:/www.unfpa. org/swp/2004/english/ch9/page5.htm. Accessed March 21, 2007.

27. Okereke E, Aradeon S, Akerele A, Tanko M, Yisa I, Obonyo B. Knowledge of safe motherhood among women in rural communities in northern Nigeria: implications for maternal mortality reduction. Reprod Health. 2013;10(57):1-12.

28. Karlsen S, Say L, Souza JP, et al. The relationship between maternal education and mortality among women giving birth in health care institutions: analysis of the cross sectional WHO Global Survey on Maternal and Perinatal Health. BMC Public Health. 2011;11(606):2-10.

29. Adepoju AO, Akanni O, Falusi AO. Determinants of child mortality in rural Nigeria. World Rural Obs. 2012;4(2):38-45.
30. Awoyemi TT, Obayelu OA, Opaluwa HI. Effect of distance on utilization of health care services in Rural Kogi State, Nigeria. J Human Ecol. 2011;35(1):1-9.

31. Azuh DE. Socio-demographic factors influencing health programme usage by mothers in Nigeria: implications for policy action. Paper submitted for Sixth African Population Conference-African Population: Past, Present and Future; December 5-9, 2011; Burkina Faso: Ouagadougou.

32. Gabrysch S, Cousens S, Cox J, Campbell O. Distance and quality of care strongly influence choice of delivery place in rural Zambia: a study linking national data in a Geographic Information System. J Epidemiol Community Health. 2011;65:A42.

33. Roy MP, Mohan U, Singh SK, Singh VK, Srivastava AK. Factors associated with the preference for delivery at the government hospitals in rural areas of Lucknow District in Uttar Pradesh. Indian J Public Health. 2013;57(4):268-271.

34. Shehu CE, Ibrahim MTO, Oche MO, Nwobodo EI. Determinants of place of delivery: a comparison between an urban and a rural community in Nigeria. J Public Health Epidemiol. 2016;8(6):91-101.

35. Worku AG, Yalew AW, Afework MF. Factors affecting utilization of skilled maternal care in Northwest Ethiopia: a multilevel analysis. BMC Int Health Hum Rights. 2013;13:20.

36. Sajedinejad S, Majdzadeh R, Vedadhir A, Tabatabaei MG, Mohammad K. Maternal mortality: a cross-sectional study in global health. Global Health. 2015;11(4):1-13.
International Journal of Women's Health

\section{Publish your work in this journal}

The International Journal of Women's Health is an international, peerreviewed open-access journal publishing original research, reports, editorials, reviews and commentaries on all aspects of women's healthcare including gynecology, obstetrics, and breast cancer. The manuscript management system is completely online and includes

\section{Dovepress}

a very quick and fair peer-review system, which is all easy to use. Visit http://www.dovepress.com/testimonials.php to read real quotes from published authors. 